\title{
The Effect of Pre-reading Discussions on Word- guessing Ability of Iranian Pre-intermediate Freshmen University Students
}

\author{
Karim Sadeghi \\ English Language and Literature Department, Urmia University, Urmia, Iran \\ Tayebeh Samadi \\ English Language and Literature Department, Urmia University, Urmia, Iran
}

\begin{abstract}
The study reported here aimed at understanding whether pre-reading discussions affected readers' ability in guessing unknown words in the text. Forty male and female pre-intermediate freshmen university students (within the age range of 18 to 26) participated in the study. A quasi-experimental intact group design was pursued. The experimental and control groups completed four sets of quizzes comprising multiple choice items on unknown words of four reading texts to tap their guessing gains. The experimental group was involved in a pre-reading discussion on the topic of the readings before doing the quizzes, while no pre-reading discussion was used for the control group. Statistical analyses revealed that: a) during quizzes, one, two, and four, there were no significant differences between the experimental and the control groups; however, the mean scores of the experimental group were higher than the control group, implying a relative positive influence of the pre-reading discussions on guessing ability of the learners; b) during quiz three the difference between the groups proved to be significant. In general, the success rate of pre-reading discussions was not considerable, challenging a implications are discussed in the paper. uni-dimensional conception of the role of pre-reading discussion in word guessing ability of readers. Further findings and implications are discussed in the paper.
\end{abstract}

Index Terms - pre-reading discussion, guessing, Iranian context

\section{INTRODUCTION}

Utilizing an initial preparing phase such as pre-reading discussions would help the class in dealing with reading texts. Research assumes that reading is an interaction between textual information and prior knowledge of the reader. From previous research, it is hypothesized that topic familiarity would significantly affect both lexical inferencing and retention, yielding greater outcomes when subjects are more familiar with a particular topic (Pulido, 2007). Bengeleil and Paribakht (2004) contend, in the process of lexical inferencing, L2 readers' prior non-linguistic knowledge interacts with contextual cues in the text to help them guess the meanings of unfamiliar lexical items. Pre-reading discussions would prepare students for a reading task by providing them with the required subject matter familiarity and background information to assist them in the reading task by facilitating the lexical guessing process.

Pre-reading tasks have been predisposed to focus on preparing the readers for linguistic difficulties in a text, and for cultural or conceptual difficulties of the text. Pre-reading activities may not just compensate for second language reader's supposed linguistic or socio-cultural inadequacies; they may also help readers to be conscious about what they do, already know and think, i.e. to activate their existing schematic knowledge (Ajideh, 2003). Swaffer (1988) argues that schematic knowledge is more influential than word knowledge. She further claims that topic familiarity facilitates language recognition, recall of concepts, and inferential guessing.

Langer (1981) and Johnson (1982), in their studies of pre-reading activities, have demonstrated the facilitative effects of activating reader's prior knowledge as relevant to understanding of the new text. For them, pre-reading activities do not only prepare readers for the concepts that follow but also make the reading task easier and connecting the new concepts more meaningful to prior knowledge.

Pre-reading discussion can concentrate on a critical argument surrounding interpretation of a reading text. Plainly, discussion tasks elicit students' personal opinions or their expectations with respect to text content or point of view. For example, if students are to read a text about World War II, prior to reading, they can represent their expectations as to what facts will be highlighted and what perspective or political approach the article will express. Discussing these issues before being engaged with the reading provides focus in the texts. In this kind of activity, the teacher provides students with a topic for argument formed in terms of a specific question. Then each student makes an argument about the topic which may or may not stand as his or her own personal view (Knutson, 1997). Knutson stresses that "discussion of these arguments beforehand provides a focal point for reading" (p. 54). 
According to Kaivanpanah and Alavi (2008), "inferencing is a reading strategy that fits into top-down and interactive models of reading because by using prior knowledge and assumptions readers move from general knowledge to the specific meanings texts express" (p. 175). Text comprehension involves inferential activity, i.e. during the process, both information from the text and from readers' world knowledge are used to make meaningful representations (Hatdizaki, 2007). Since vocabulary is an influential component in the learning process, learners with different proficiency levels encounter situations where they understand only part of the written text or a sentence due to the fact that they do not know all the words. Encountering some unknown words might not block the overall understanding of the text, but will break down if too many words or the most essential ones are unknown (Soria, 2001). Soria maintains, using contextual cues, students draw on their knowledge of the world and the co-text to help them in word inferencing. Learners can be provided with the required knowledge base and familiarity with the subject matter of texts during whole class prereading discussions.

Haastrup (1991) gives a classification of knowledge sources used in lexical inferencing. His classification includes: intralingual, interlingual and contextual knowledge sources. Intralingual knowledge comprises knowledge of the target language syntax and target word phonology/orthography, morphology, lexis, word class, collocations, and semantics. Interlingual knowledge comprises knowledge of L1 and other languages. Contextual knowledge involves knowledge of text content or co-text, and knowledge of the world. Haastrup also distinguishes between holistic inferencing, and analytic processing. The former involves prediction on the basis of context, that is, drawing on world knowledge in the form of schematic or conceptual knowledge (p. 124), and the latter involves analytic processing, which is based on analysis of the linguistic features of the target word. Another taxonomy for knowledge sources is introduced by Paribakht and Wesche (1999) which consists of linguistic sources (knowledge of discourse, sentence-level grammar, word morphology, word associations, cognates, homonyms, and punctuation) and extralinguistic sources (topic and world knowledge). In both Haastrup, and Paribakht and Wesche' classifications, topic and world knowledge are considered important factors useful for lexical guessing. Background knowledge of the subject of a passage plays a critical role in successful guessing ( $\mathrm{Na}$ and Nation, 1985).

It seems that, pondering over the body of research done so far, pre-reading discussion and the direct role it might play in activating the learners' schemata, as a result of which learners may have successful guess of unfamiliar word meanings, therefore, facilitating the reading fluency of language learners, has received much less elaborate exploration by researchers in the field of second language acquisition, SLA. Accordingly, the present study tried to push the current status of research on pre-reading discussions' influence on students' lexical guessing a step forward towards this goal. Also, the proposed task has not been sufficiently tackled in Iranian English language learning contexts; therefore, implementing a research to provide insights to illuminate its advantage seems necessary.

Accordingly, the objective of the present study was to explore the influence of pre-reading discussions on Iranian freshmen university students' ability in contextually guessing the meanings of unknown words in reading their general English course book after the accomplishment of the pre-reading discussion task.

More precisely, this study sought to find answers to the following question:

Is there any relationship between pre-reading discussions and university freshmen students' ability in guessing unfamiliar words from the reading context?

The following null-hypothesis was put forward for the above question to be tested at the probability level of 0.05 :

There is no relationship between pre-reading discussions and university freshmen students' ability in guessing unfamiliar words from the reading context.

\section{MATERIALS AND METHODS}

The study followed an intact group design. Two university classes who were doing their general English course were selected. Randomly one of the classes was assigned as the "treatment group" and the other as the "control group". The study is a typical quasi-experimental one involving a comparison between two groups, the control and the treatment. This involves the comparisons between the word guessing gains across groups. The study was conducted during the autumn 2011 semester.

All participants were Iranian university freshmen students taking their general English course at Afagh private university in Urmia, West Azerbaijan. Semi-randomly assigned, the control group class subjects included Herbaceous Medicines major students and the treatment group participants were majoring at Horticulture. The study involved both males and females aged 18 to 26 years. The participants' homogeneity in experimental and control groups was ensured using a modified version of PET (Preliminary English Test) as the proficiency and screening pre-test. Out of the 71 males and females students who participated in the study only 40 students could be considered for the study and statistical analyses. Participants who missed either the pre- or post-tests and more than two experiment quizzes were excluded from the study. Twenty students in each class were involved in the study. For the ease of administration, the PET test was adapted to cover only reading and vocabulary sections. The estimated reliability amounted to be $\mathrm{r}=0.71$.

The course book for both groups was Select Readings (Pre-Intermediate Student Book) by Linda Lee and Erik Gunderson (2002), which was taught as the instructional material and used as a source of treatment. Four texts used in the experiment were adapted from four chapters of the Select Readings to manifest similar levels of linguistic complexity, topic familiarity, relatively equal difficulty, and to have a parallel discourse structure and appropriate for 
students with relatively low reading skills. The first reading passage was on "studying in an English speaking country"; the second was on "building a successful business"; the third was on "a ghost story"; and the fourth passage was on "volunteering for a humanity organization". One of the researchers was the course instructor for both the treatment and control groups.

Four quizzes were made ranging from 10 to 15 items each, intended to tap the word inferencing abilities of the readers. Quiz one included 10 target word items because of the relative shortness of its reading text. Obscure words which were considered to be unknown to pre-intermediate students were chosen from the reading texts as target lexical items. Since the homogeneity of the groups was substantiated by a pre-test, it proved sensible that the selected words were of the same level of familiarity for the participants. In each item, the word's line number in the reading text was given so that the students could find the targeted words easily. There are four choices in each item, three alternatives to choose from ( $a, b, \&$ c), and the fourth one, (d) was left blank for the students to write the word's meaning in Farsi in case they could not choose from the given word choices. The participants were given roughly 10 minutes to complete each lexical guessing quiz. They were informed that there was not a negative score for their wrong responses, so they were asked not to leave any questions unanswered. In addition, the participants were not allowed to use dictionaries, nor were they allowed to ask for their partner's help.

Pre-reading discussions were used in the treatment group. For this purpose, a set of pre-reading activities in the form of pre-reading questions were prepared to stimulate students' participation in class discussions. For example, for "volunteering for a humanity organization" reading topic, the researcher in charge asked this pre-question: What do you think about the role of Habitat other than building houses for the poor? Two of the discussion procedures introduced by Richards and Schmidt (2002, p. 164) were also used in the present study; 'reflective discussion' and 'guided discussion' the aim of which were to activate the students background knowledge and provide the necessary prior information for students to ease the inferencing process for them. Furthermore, reading texts' relevant pictures were displayed through a video projector to stimulate discussions. The topics discussed in the pre-reading discussion group (treatment group) included four topics of the four reading texts: studying in an English speaking country, building a successful business, a ghost story, and volunteering for a humanity organization. The readings topics were put on the board and the students were asked to present their ideas on the topic which were then written on the board. For example, the ideas presented for discussion on the topic of "studying in an English speaking country" involved: university, studying abroad, homestay, transportation, accommodation, parents' advice, British culture, nation's impressions about different countries and cultures, and why it is important to learn English. The students also talked about the problems of accommodation and places where they would have preferred to live if they were to study in another country or city.

The study was conducted over a 15-session academic semester; however, the researchers could only use four sessions to carry out the study. The study's instructional sessions were aligned with an ongoing university program. Every session lasted 90 minutes and the pre-reading discussions lasted about 30 to 45 minutes for each session of the treatment group. In the control group, however, as it is usual in most language classes, the teacher asked the students to read the reading text right away without any pre-reading discussions. Instead of answering comprehension questions which usually follow the reading, the participants in both groups were asked to answer the lexical guessing quiz items while reading the texts individually.

The homogeneity and comparability of the subjects in treatment and control groups at the beginning of the study were substantiated via an independent t-test which was carried on the scores gained from the PET pre-test. Furthermore, four independent t-test analyses were applied to compare the score gains of four word guessing quizzes to observe any significant differences between the treatment and control groups in terms of their word guessing ability.

\section{RESULTS}

Table 1 displays the PET pre-test results for the treatment and control groups. The estimated language proficiency mean and standard deviation of the participants in the treatment group amounted to 8.45, out of 25, and 2.978, respectively, and the estimated mean and standard deviation of the participants in the control group amounted to 6.95 and 4.036, respectively. An independent t-test was run to measure the difference in the pre-tests' mean scores. The analysis showed that there was no significant difference between the treatment and control groups in terms of their language proficiency. In other words, the treatment and the control groups proved to be homogenous and comparable at the beginning of the study.

TABLE 1.

PRE-TEST DESCRIPTIVE ABD INFERENTIAL STATISTICS FOR EXPERIMENTAL AND CONTROL GROUPS

\begin{tabular}{|l|l|l|l|l|l|l|l|l|}
\hline Groups & No. of Students & Mean & Variance & Std. Dev. & Std. Err & DF & Mean Diff. & P-value \\
\hline Treatment & 20 & 8.45 & 8.866 & 2.978 & 0.666 & \multirow{2}{*}{38} & \multirow{2}{*}{0.962} \\
Control & 20 & 7.48 & 18.319 & 4.280 & 0.957 & 0.4142 \\
\hline
\end{tabular}

As it is mentioned above, there were 10 target word items for quiz one. So for the ease of analysis and calculation, the scores for this quiz were all also calculated out of 15 for each participant. Table 2 displays that for quiz one, the mean score of the treatment group (Mean=10.26, $\mathrm{SD}=3.004$ ) is higher than the mean score of the control group 
(Mean=10.05, $\mathrm{SD}=3.173$ ); however, the difference between the groups in terms of lexical guessing gains is not statistically significant. Hence, the null hypothesis is accepted for the first guessing quiz.

TABLE 2.

DESCRIPTIVE AND INFERENTIAL STATISTICS FOR LEXICAL GUESSING QUIZ ONE

\begin{tabular}{|l|l|l|l|l|l|l|l|l|}
\hline Groups & No. of Students & Mean & Variance & Std. Dev. & Std. Err & DF & Mean Diff. & P-value \\
\hline Treatment & 19 & 10.26 & 10.066 & 3.004 & 0.672 & \multirow{2}{*}{37} & \multirow{2}{*}{0.213} \\
Control & 20 & 10.05 & 9.024 & 3.173 & 0.728 & \multirow{2}{*}{0.8305} \\
\hline
\end{tabular}

For quiz two, as Table 3 shows, the difference between the groups in terms of lexical guessing gains is not statistically significant although the mean score of the treatment group (Mean=10, $\mathrm{SD}=2.749$ ) is higher than the mean score of the control group (Mean=8.35, $\mathrm{SD}=2.390$ ). Hence, the null hypothesis is accepted for the second guessing quiz too, although there is a trend for significance because the P-value is very near the alpha level.

TABLE 3.

DESCRIPTIVE AND INFERENTIAL STATISTICS FOR LEXICAL GUESSING QUIZ TWO

\begin{tabular}{|l|l|l|l|l|l|l|l|l|}
\hline Groups & No. of Students & Mean & Variance & Std. Dev. & Std. Err & DF & Mean Diff. & P-value \\
\hline Treatment & 18 & 10 & 7.556 & 2.749 & 0.631 & \multirow{2}{*}{37} & \multirow{2}{*}{1.650} \\
Control & 20 & 8.35 & 5.713 & 2.390 & 0.534 & \multirow{2}{*}{0.0525} \\
\hline
\end{tabular}

For quiz three, as Table 4 shows, the difference between the groups in terms of lexical guessing gains is statistically significant $(\mathrm{P} \leq 0.05)$ and the mean score of the treatment group (Mean=9.05, $\mathrm{SD}=2.877)$ is higher than the mean score of the control group (Mean=7.25, $\mathrm{SD}=2.613$ ). Hence, the null hypothesis is rejected for the third guessing quiz.

TABLE 4.

DESCRIPTIVE AND INFERENTIAL STATISTICS FOR LEXICAL GUESSING QUIZ THREE

\begin{tabular}{|l|l|l|l|l|l|l|l|l|}
\hline Groups & No. of Students & Mean & Variance & Std. Dev. & Std. Err & DF & Mean Diff. & P-value \\
\hline Treatment & 19 & 9.05 & 8.275 & 2.877 & 0.660 & \multirow{2}{*}{37} & \multirow{2}{*}{1.803} & \multirow{2}{*}{0.0475} \\
Control & 20 & 7.25 & 6.829 & 2.613 & 0.584 & & \\
\hline
\end{tabular}

For quiz four, Table 5 shows that the difference between the groups in terms of lexical guessing gains is not statistically significant although the mean score of the treatment group (Mean=8.15, SD=2.889) is higher than the mean score of the control group (Mean=7.1, $\mathrm{SD}=3.401$ ). Hence, the null hypothesis is accepted for the fourth guessing quiz.

TABLE 5

DESCRIPTIVE AND INFERENTIAL STATISTICS FOR LEXICAL GUESSING QUIZ FOUR

\begin{tabular}{|l|l|l|l|l|l|l|l|l|}
\hline Groups & No. of Students & Mean & Variance & Std. Dev. & Std. Err & DF & Mean Diff. & P-value \\
\hline Treatment & 20 & 8.15 & 8.345 & 2.889 & 0.646 & \multirow{2}{*}{38} & \multirow{2}{*}{1.050} \\
Control & 20 & 7.10 & 11.568 & 3.401 & 0.761 & \multirow{2}{*}{0.2993} \\
\hline
\end{tabular}

\section{DISCUSSION}

The mean score results of the four guessing quizzes showed that the treatment group participants performed relatively better than those in the control group in guessing the target words, although statistically significant relationships were not observed between pre-reading discussions and the participants' performance on lexical guessing quizzes one, two, and four, except for quiz three where the difference proved to be significant $(\mathrm{p} \leq 0.05)$. Findings of this research, though not very strong, somehow paved the way for accepting the belief that giving prior information through discussions in the pre-reading stage might have a relative positive impact on reading process and lexical guessing ability in particular.

Considering the relative outperformance on the part of the treatment group, the findings concur to some extent with those by Langer (1981) and Johnson (1982) regarding the fact that pre-reading activities such as pre-reading discussion and brain storming can increase students' interest and help them construct mental models for the incoming text. Langer and Johnson maintain that pre-reading discussions prepare readers for the concepts that follow and make the reading task easier and connect the new concepts more meaningfully to prior knowledge. Eskey (1988) believes that new information, new concepts, and new ideas can have meaning when they can be related to something the individual already knows. However, the results reported above are not consistent with the arguments previously made for using pre-reading activities such as pre-reading discussions (e.g., Bügel \& Buunk, 1996; Alvermann, Smith, \& Readence, 1985; Tudor, 1989; Richards, Li \& Tang, 1995; Knutson, 1997; Applebee, Langer, Nystrand, \& Gamoran, 2003; Widodo, 2009; Nation, 2009; Yusuf, 2011).

In the literature, there is a combination of factors that influence L2 readers' lexical inferencing; these include textrelated and reader-related variables a combination of which affects lexical inferencing (Kaivanpanah and Alavi 2008). This study tried to examine the effect of a single variable i.e. providing prior information and activating background knowledge through pre-reading discussions on lexical guessing ability of students, which seems to be a uni-dimensional study about the lexical guessing ability of students. Reader-related and text-related factors such as vocabulary knowledge of the students could have dramatically influenced the results of the study. Qian's (2005) study showed that 
a positive relationship existed between learners' vocabulary knowledge and their lexical inferencing ability. Furthermore, Kelly (1990) argues that when readers come across unknown words, they may be unable to make use of available contextual clues because when there exists a large number of unknown to known words, learners may be unable to use contextual clues for inferencing meaning, hence readers' vocabulary knowledge is an essential prerequisite for inferencing. The participants of this study who had an elementary level of language proficiency are not expected to have had a large vocabulary repertoire to ease the guessing task for them.

In addition, learners' language proficiency is a potential factor affecting the inferencing ability of the learners. Advanced L2 learners, Kaivanpanah and Alavi (2008) argue, tend to infer more because they know enough words; and using the sufficient and clear context created by the known words, they can infer the meaning of unknown words better. Since the participants involved in this study were of a pre-intermediate level of language proficiency, they could not benefit from the pre-reading discussions efficiently; therefore, the findings of the study seem to be in line with Aebersold and Field's (1997) who argue that lower level students may have the schemata but not the necessary linguistic skills in the second language to benefit them when guessing, so teachers have to introduce the relevant vocabulary during the discussion; otherwise, the schema may be activated but the L2 reading process may not be facilitated for the students. They note that although pre-reading activities, such as pre-reading discussions, are potentially beneficial, their usefulness is limited. Furthermore, Morrison's (1996) study showed that high-proficiency learners are more successful than low-proficiency learners at guessing the meanings of unfamiliar words correctly in reading texts; this may be due to the low-proficiency readers' limited lexical knowledge.

As a limitation of the present study, there were not enough sessions to see the long-term effect of pre-reading discussions on guessing. A greater number of pre-reading discussion sessions could have made the results of the study more generalizable and predictive. Similarly, a higher number of reading texts to apply pre-reading discussions is needed to study the effect of discussions.

\section{CONCLUSION}

The research survey which opened this study highlighted the role of pre-reading discussions in word guessing ability of an EFL population and the importance of pre-reading discussions in enhancing language achievement. The results provide evidence that pre-reading discussions may have a potential for enhancing the lexical guessing ability of students. The study offered a relative degree of empirical support to the theoretical considerations relating to the positive role of pre-reading activities, and pre-reading discussions in particular, in the students' lexical guessing ability outlined above and also to the use of pre-reading discussions in English language reading classes.

There are many factors which interact with each other to influence the reading process and lexical guessing in particular. These factors are both related to readers and texts. Nassaji (2003), for example, mentions that lexical inferencing depends on students' language and comprehension skills, the types of texts and tasks, the nature of the word, and a number of other learner-related differences. Its success involves the use of appropriate strategies and also the combination of those strategies with many other skills and knowledge sources both inside and outside the text. Therefore, a combination of these factors are supposed to be more efficient in facilitating the guessing task, although the use of pre-reading discussions which provide prior information to the students and activate their existing background knowledge to ease the connection between what they already know and the text content can be suggested to facilitate this inferencing process.

A great deal of information can be found by getting learners to introspect aloud while they guess from context. Information from such studies provides valuable illuminating data on students' guessing behaviors. Future research might include observation of classroom behavior, using a classroom observation scheme. Also verbal reports are a tool for the classroom teacher in getting readers to verify what they are doing while they are reading and guessing. Students' perceptions of the factors contributing to their behavior in class can also be elicited through structured interviews designed to elicit introspective comments from participants.

Replication with other populations is clearly called for before the conclusions given above could be maintained with confidence. Also, experimentation with a wider range of texts and words is clearly warranted. The L2 proficiency factor could be investigated further to assess more accurately how proficiency level interacts with the need of and the response to pre-reading discussions.

\section{REFERENCES}

[1] Aebersold, J. A., \& Field, M. L. (1997). From reader to reading teacher. Cambridge: Cambridge University Press.

[2] Ajideh, P. (2003). Schema-theory based pre-reading tasks: A neglected essential in the ESL reading class. The Reading Matrix, 3, 1-14.

[3] Alvermann, D. E., \& Smith, L. C., \& Readence, J. E. (1985). Prior knowledge activation and the comprehension of compatible and incompatible text. Reading Research Quarterly, 20, 420-436.

[4] Applebee, A. N., Langer, J. A., Nystrand, M., \& Gamoran, A. (2003). Discussion-based approaches to developing understanding: Classroom instruction and student performance in middle and high school English. American Educational Research Journal, 40, 685-730. 
[5] Bengeleil, N. F., \& Paribakht, T. S. (2004). L2 reading proficiency and lexical inferencing by university EFL learners. The Canadian Modern Language Review, 61, 225-249.

[6] Bügel, K. \& Buunk, B. P. (1996). Sex differences in foreign language text comprehension: The role of interests and prior knowledge. Modern Language Journal, 80, 15-31.

[7] Eskey, D. E. (1988). Holding in the bottom: An interactive approach to the problem of sound language readers. In P. L. Carrell, J. Devine, J. \& D. E. Eskey (Eds.), Interactive approaches to second language learning (pp. 130-152). New York: Cambridge University Press.

[8] Haastrup, K. (1991). Lexical inferencing procedures or talking about words: Receptive procedures in foreign language learning with special reference to English. Tubingen, Germany: Gunter Narr Verlag.

[9] Hatzidaki, A. (2007). The process of comprehension from a psycholinguistic approach implications for translation. Translators' Journal, 52, 13-21.

[10] Johnson, P. (1982). Effect on reading comprehension of building background knowledge. TESOL Quarterly, 16, 503-16.

[11] Kaivanpanah, S., \& Alavi, S. M. (2008). The role of linguistic knowledge in word-meaning inferencing. System, 36, $172-195$.

[12] Kelly, P. (1990). Guessing: No substitute for systematic learning of lexis. System, 18, 199-207.

[13] Knutson, E. M. (1997). Reading with a purpose: Communicative reading tasks for the foreign language classroom. Foreign Language Annals, 30, 49-57.

[14] Langer, J. A. (1981). From theory to practice: a pre-reading plan. Journal of Reading, 25, 152-156.

[15] Lee, L., \& Gunderson, E. (2002). Select readings pre-intermediate: student book. USA: Oxford University Press.

[16] Morrison, L. (1996). Talking about words: A study of French as a second language learners' lexical inferencing procedures. The Canadian Modern Language Review, 53, 41-67.

[17] Na, L., \& Nation, I.S.P. (1985). Factors affecting guessing vocabulary in context. RELC Journal. 16, 33 - 42.

[18] Nassaji, H. (2003). L2 vocabulary learning from context: strategies, knowledge sources, and their relationship with success in L2 lexical inferencing. TESOL Quarterly 37(4), 645-670.

[19] Nation, I.S.P. (2009). Teaching ESL/EFL reading and writing. New York: Rutledge.

[20] Paribakht, S., \& Wesche, M. (1999). Incidental vocabulary acquisition through reading: An introspective study. Studies in Second Language Acquisition, 21, 203-220.

[21] Pulido, D. (2007). The effects of topic familiarity and passage sight vocabulary on L2 lexical inferencing and retention through reading. Applied Linguistics, 28, 66-86.

[22] Qian, D. D. (2005). Demystifying lexical inferencing: The role of aspects of vocabulary knowledge. TESL Canada Journal, 22, 34-54.

[23] Richards, J. C., Li, B., \& Tang, A. (1995). A Comparison of pedagogical reasoning skills in novice and experienced ESL teachers. RELC Journal, 26, 1-24.

[24] Richards, J. C., \& Schmidt, R. (2002). Longman dictionary of language teaching and applied linguistics. ( ${ }^{\text {rd }}$ ed.). London: Longman.

[25] Soria, J. (2001). A study of Ilokano learners' lexical inferencing procedures through think-aloud. Second Language Studies, 19, 77-110.

[26] Swaffer, J. K. (1988). Readers, texts, and second languages: the interactive process. The Modern Language Journal, 72, 123149.

[27] Tudor, I. (1989). Pre-reading: A categorization of formats. System, 17, 323-338.

[28] Widodo, H. P. (2009). Key issues in teaching EFL/ESL intensive reading: A videotaped self-observation report. The Journal of Effective Teaching, 9, 38-58.

[29] Yusuf, H. O. (2011). The effect of pre-reading activities on students' performance in reading comprehension in senior secondary schools. Educational Research, 2, 1451-1455.

Karim Sadeghi is an academic member at Urmia University, Iran. His publications have appeared in Asian EFL Journal, The Asia Pacific Education Researcher, The Modern Language Journal, Canadian Journal of Linguistics and TESL Canada Journal among others.

Tayebeh Samadi is an MA candidate in TEFL at Urmia University, Iran. 